DOI: 10.11606/issn.2238-3867.v15i2p266-274

sala preta

ppgac

Dossiê espetáculo: Christiane Jatahy

\title{
Do corpo e da tela: especificidade e hibridismo na zona fronteiriça do teatro com o cinema
}

Body and screen: Specificity and hybridity in the border area between theatre and cinema

\section{Luciana Eastwood Romagnolli}

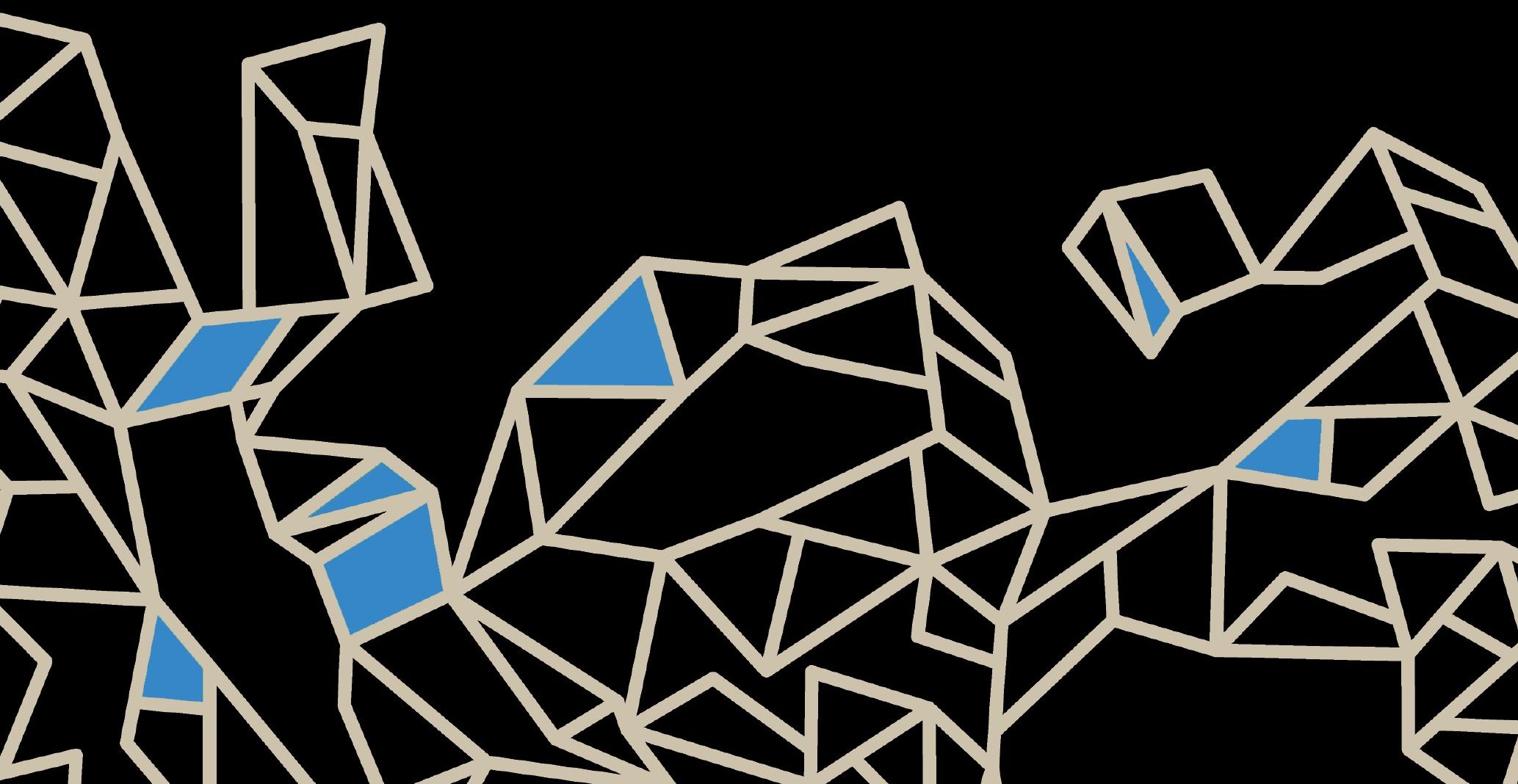




\section{Resumo}

Este artigo analisa a obra da encenadora Christiane Jatahy como propositora de uma pesquisa radical sobre as relações entre teatro e cinema, por meio da observação crítica de dois espetáculos - Julia (2011) e E se elas fossem para Moscou? (2014) -, considerando o jogo realizado com as especificidades de cada uma dessas artes e suas artesanias próprias, as experiências do convívio e do tecnovívio, assim como as zonas de hibridismo entre elas, com base em conceituações de Erika Fischer-Lichte, Jorge Dubatti e Jean-Louis Comolli.

Palavras-chave: Teatro, Cinema, Convívio, Tecnovívio.

\section{Abstract}

This article analyzes the work of theatre director Christiane Jatahy as a radical researcher of the relationship between theater and cinema, through critical observation of two plays - Julia (2011) and What if they went to Moscow? (2014) -, considering the work with the specificities of each of these arts and their own processes, the experiences of conviviality and technoviviality, as well as the hybrid zones between them, based on concepts of Erika Fischer-Lichte, Jorge Dubatti and Jean-Louis Comolli.

Keywords: Theatre, Cinema, Conviviality, Technoviviality.

"Talvez isso não seja uma peça. Talvez não seja um filme também. Ou talvez sejam as duas coisas ao mesmo tempo" (JATAHY, 2014). Com estas três frases, a atriz Isabel Teixeira demarca a imprecisão dos limites de $E$ se elas fossem para Moscou? (2014) como zona fronteiriça entre o teatro e o cinema, onde ambas as linguagens são tensionadas uma em direção à outra, especialmente em categorias como presença/ausência, materialidade/ virtualidade, territorialização/desterritorialização: pares dicotômicos não mais excludentes, que operam num regime de ambivalência - próprio da estética performativa ao se valer da capacidade da performance de "desestabilizar e até colapsar oposições binárias" (FISCHER-LICHTE, 2008, p. 25) - acionando as matrizes convivial e tecnovivial (DUBATTI, 2014) como experiências 
opostas e complementares para o espectador. É algo semelhante ao que a diretora Christiane Jatahy já propunha no espetáculo anterior, Julia (2011), por meio de uma configuração cênica que privilegiava o teatro como obra de arte total, que inclui na composição da cena, além dos recursos performáticos, textuais, pictóricos, escultóricos e musicais, também o audiovisual.

A seu modo, Julia efetiva um embate entre o específico teatral e o específico cinematográfico, travado diante do público de modo a lhe solicitar, indivíduo a indivíduo, uma série de escolhas sobre o que e como ver, que explicitam o "gesto propriamente artístico" do espectador (DESGRANGES, 2012, p. 24). E se elas fossem para Moscou?, por sua vez, separa as duas linguagens, porém preserva justamente as margens de indistinção entre elas, convocando então o espectador a um gesto de comparação, reconstituição e composição a partir de partes complementares, verso e reverso, ao assistir à peça sendo filmada e ao filme montado a partir das cenas gravadas, apresentados simultaneamente em salas contíguas para públicos distintos mas que, a seu tempo, transitarão entre as duas plateias.

$\mathrm{Na}$ produção artística brasileira, Jatahy vem sendo a propositora das pesquisas mais radicais sobre as relações entre teatro e cinema como linguagens e experiências distintas e aproximáveis e sobre as possibilidades existentes nesse entre. Eis um percurso que já propiciou experimentos diversos, como incorporar ao vivo à cena teatral os procedimentos de corte e montagem típicos da linguagem cinematográfica em Corte seco (2009), ou a criação de um longa-metragem híbrido de documentário e ficção a partir da peça $A$ falta que nos move (2005) - proposta, embora semelhante à de $E$ se elas fossem para Moscou? no duplo desdobramento teatral-fílmico, diversa por proporcionar tais experiências desligadas no tempo e no espaço. No caso de Julia e E se elas fossem para Moscou?, outra característica em comum emerge do trabalho criativo de Jatahy: a livre adaptação dos clássicos da dramaturgia Senhorita Julia, de August Strindberg, e As três irmãs, de Anton Tchekhov, para um contexto, uma linguagem (no sentido linguístico de fato, da fala oral, do vocabulário e da prosódia) e uma sensibilidade contemporâneas, preservando somente os personagens centrais. Desse modo, Julia recria o conflito forjado por Strindberg no Rio de Janeiro atual, transformando-o em um embate entre três formas de opressão - a de classe e a racial, 
exercidas por Julia (e o pai, embora ausente) sobre Joelson, e a de gênero, exercida por Joelson sobre Julia, sobretudo ao desqualificá-la pela atividade sexual. E se elas fossem para Moscou?, a seu tempo, acentua a ansiedade das irmãs Olga, Maria e Irina em relação ao rumo de suas vidas, transpondo suas inquietações para a realidade contemporânea, como quando Irina troca fotos de automutilação com um rapaz por meio de mensagens de celular, que exibe para o público.

Assim como promove a travessia do passado para o presente na dramaturgia textual, a diretora parece conceber o que seria um teatro contemporâneo justamente no entrecruzamento cênico dos corpos material e virtual. Nesse sentido, os trabalhos de Jatahy demonstram um movimento duplo e integrado. De um lado, o investimento no convívio como especificidade teatral, com a compreensão de que a zona de experiência (semiótica e não semiótica) fundada pela copresença dos corpos de espectadores e atores no mesmo cruzamento espaço-temporal faz do teatro um lugar de resiliência em relação à realidade social de relações altamente virtualizadas; lugar este em que circulam afetações sensuais fenomênicas e é possível o encontro que leve à construção conjunta de um mundo ficcional, do qual o espectador também é criador como partícipe do acontecimento teatral. Do outro lado, o investimento na potência da geração tecnológica de imagens, que ampliam o território do visível e do imaginável, correspondentes aos modos de percepção vigentes no nosso tempo - conforme observado por Jonathan Crary (2014), a partir da popularização do cinema, da televisão e dos dispositivos móveis. O tecnovívio, nas palavras de Jorge Dubatti (2014), seria essa "cultura vivente desterritorializada por intermediação tecnológica". Confluem, assim, duas formas distintas de elaboração poética: a convivial e a tecnovivial, que compõem paradigmas distintos de relação com o mundo.

Em Julia, a atriz Julia Bernat executa a triangulação entre a realidade compartilhada com os espectadores e a ficção da fábula representada ao vivo, filmada e projetada no telão-cenário. Transita entre as camadas que compõem o espetáculo ao entrar e sair da personagem homônima, endereçando aos espectadores olhares e questionamentos sobre as atitudes de sua contraparte ficcional. Nesse reconhecimento do espectador como uma alteridade presente, ela evidencia a dimensão do convívio, implicando aqueles a 
quem interpela no acontecimento teatral, como quem os convoca como testemunhas e os impede de se esquecer de que estão ali - algo que comumente sucede no cinema clássico, ao se projetar a imaginação para dentro da ficção a partir da identificação com o olhar da câmera e com um personagem, mas também, por vezes, de modo semelhante, no teatro de quarta parede, cuja iluminação e configuração espacial constroem esse apagamento do ser-estar do público. De certo modo, é possível pensar que, em Julia, os corpos dos atores mediam a relação entre o espectador e a imagem cinematográfica.

Ao mesmo tempo, o espetáculo aponta para o real de sua artesania ao expor os mecanismos de fabricação da imagem cinematográfica, na medida em que um cameraman registra as atuações aos olhos dos espectadores, que veem, simultaneamente, a cena apresentada e a projetada no telão; o artifício do quadrado revestido de folhagem e a imagem projetada de um jardim; o cenário armado atrás do telão e o quarto do personagem Joelson. As dimensões disponíveis ao olhar do espectador estão, portanto, quadruplicadas: a representação teatral e a cinematográfica, assim como suas respectivas artesanias. Tais possibilidades evidenciam o ato do espectador como o de seleção de onde depositará sua atenção (e, diante da impossibilidade de apreensão do todo, a montagem dessas partes para compor um conjunto particular, que constituirá a sua visão do espetáculo, única e intransferível). A cena emblemática da necessidade de escolha e do tipo de implicação que gera para o espectador é o ato sexual representado por Julia Bernat e Rodrigo do Santos no cenário do quarto de Joelson, que o espectador consegue somente entrever através das paredes do cenário. Indaga a cena: "para onde olhar?". No telão, os corpos nus de Julia (a personagem?) e Joelson (e Rodrigo?) iludem o sexo explícito. Na fresta visível, a câmera e os pedaços de corpos fenomênicos em atuação, suficientes para que se perceba o que se passa, sem a explicitação erótica da imagem cinematográfica, mas com a capacidade de afetação sensual própria dos corpos fenomênicos. O que a encenação assim armada explicita, sobretudo, é o lugar de voyeur do espectador, seja ao despender esforço para ver o corpo-material nu, seja ao focar o simulacro fetichizado do ato sexual; e cada uma dessas opções implica uma ética do olhar, um regime de expectação distinto. Cabe aqui a observação de Regis Debray (1993), segundo o qual "olhar não é receber, mas colocar em ordem o visível, organizar a 
experiência" (p. 42). Duplo gesto novamente: o da escolha do que olhar e o da organização do visível, o que coloca o espectador diante do próprio processo que constitui o seu ato de criação do que vê a partir do que lhe é mostrado. $O$ espectador, então, a todo tempo é convocado a posicionar-se, ainda que silenciosamente, diante da relação entre a materialidade dos atores e as imagens projetadas, oscilando entre afetar-se pelo tônus da presença ou adentrar a ilusão de ausência presente de um mundo fantasmagórico; entre a territorialidade do vínculo espaço-temporal compartilhado pelos corpos fenomênicos ou a desterritorialização propiciada pelas imagens projetadas na tela. Opções não excludentes, cujos sentidos e efeitos entrecruzam-se.

Se emprestarmos de Erika Fischer-Lichte $(2008,2012)$ a classificação sobre os graus da presença (fraca, forte e radical), é possível pensar em termos semelhantes o convívio desdobrado em três conceitos graduais. $\mathrm{O}$ conceito fraco de convívio teatral seria a copresença de corpos no mesmo espaço-tempo (DUBATTI, 2007), ou seja, estar "aqui" e "diante do olhar atento de um outro" (FISCHER-LICHTE, 2012, p. 106), base da maioria dos trabalhos teatrais. Um conceito forte seria o de um convívio intensificado pelo reconhecimento da presença do espectador, investindo-a de atenção, pela ruptura da quarta parede, o endereçamento de olhares e a interpelação direta do público, reforçando o eixo extraficcional, como se vê em Julia. Um conceito radical seria aquele que faz do convívio ordinário um evento, de modo que a copresença do espectador é transfigurada por um gesto relacional (BOURRIAUD, 2009), que o convoca como participante pleno do acontecimento teatral, seja por lhe atribuir um papel ou tarefas, seja pela demanda por memória e outras informações que o impliquem diretamente na construção dramatúrgica. É o caso da peça E se elas fossem para Moscou?, quando os espectadores assumem o papel de convidados para a celebração de aniversário de Irina, alguns bebem espumante, entram em cena e dançam com as atrizes.

A natureza dessa relação convivial, tal qual o teatro em si, é efêmera. Isso quer dizer que, embora a peça seja armada com tal configuração, não implica necessariamente a efetivação de qualquer tipo de comunhão entre espectadores e artistas, nem mesmo que o espectador se reconheça no papel que lhe é atribuído - como o de convidado. Tal identificação, contudo, não é necessária, pois é também da ordem do jogo: uma proposição para que o 
espectador jogue o jogo cênico e fabule com os atores. Outra possibilidade de se pensar o convívio no sentido radical seria a instauração de uma experiência, impossível, porém, de ter sua efetividade aferida se não a partir da vivência de cada espectador individualmente.

No plano da peça, então, o convívio teatral é reforçado pelas falas confessionais direcionadas à plateia e por uma intimidade forjada pela relação direta de olhares, pedidos e convites. Ao mesmo tempo, a presença das câmeras é ostensiva e algumas cenas são feitas para as lentes, a ponto de uma das atrizes pedir a um espectador que ajuste o enquadramento de um close, o que gera um estranhamento na pretensa familiaridade instaurada e altera a situação do público, não mais de meras testemunhas da ficção das três irmãs, mas também da construção do filme ao vivo. Novamente, o ato de seleção lhe é demandado, agora em relação às múltiplas ações que se realizam simultaneamente pelas três atrizes e entre o dentro (a fábula) e o fora (a filmagem) da ficção.

Outra vez, também, é possível eleger uma cena emblemática da tensão entre teatro e cinema configurada entre a peça e o filme homônimos: quando a atriz Stella Rabelo representa um ato de masturbação no limite entre dor e prazer. São afetos e constrangimentos distintos os que se produzem na sala de teatro e na sala de cinema diante daquele corpo e da imagem do corpo. No cinema, o espectador está, a seu modo, salvaguardado do risco do real que o convívio sustenta. $O$ corpo que se debate na deficiência do gozo é só imagem capturada, não carne indomável. $O$ espectador está só na escuridão, e em sua solidão outro tipo de intimidade se estabelece, uma vez que a situação cinematográfica exige dele a suspensão das relações com o que não seja a superfície da tela de projeção, a restrição da mobilidade corporal e a adesão, por vontade própria, à crença na verdade dos simulacros (COMOLLI, 2008, p. 186), para a constituição de um imaginário ao modo da primeira infância: a crença na imagem que está diante de si como uma presença, isto é, a inconsciência da ausência daquilo que se vê (AUMONT, 2005 p. 252). Por tais especificidades é que se instaura uma relação íntima entre o espectador e a imagem diante de si, a qual the é apresentada em planos fechados, closes, ângulos e detalhes impossíveis ao espectador teatral, assim como a cenas e depoimentos exclusivos. Para um, a copresença física; para outro, a proximidade sobre-humana do plano fechado em um olhar. 
Na peça, há um constante presente, pontuado por alusões ao futuro em Moscou que não se concretizam. No filme, as relações temporais se alteram: já não mais o antes e o alhures do filme versus o presente do espectador; os tempos de captação da imagem e de projeção praticamente coincidem, na medida em que a diretora Christiane Jatahy opera a montagem em tempo real em uma sala apartada de ambas as plateias, instaurando uma relação renovada do espectador do cinema com o tempo daquilo que vê. $\mathrm{O}$ alhures, porém, é o que permanece como a distância entre público e obra, de modo que os espectadores não são capazes de afetar os atores na tela - eis a ironia: não estes espectadores do filme, mas, sim, os da peça o são. Nas palavras de Jean-Louis Comolli, "o filme e o espectador estão na sessão ao mesmo tempo presentes e ausentes um para o outro" (COMOLLI, 2008, p. 213), em razão do descompasso, ou, neste caso, em que são simultâneas, da distância geográfica entre a produção e a projeção.

$O$ projeto duplo de $E$ se elas fosse para Moscou? separa essas duas experiências distintas para ao fim reuni-las, abalando as dicotomias ao inverter as relações que regiam cada espaço. $\mathrm{Na}$ sala de teatro, a presença das atrizes é suprimida, interrompendo o convívio, substituída pela tela que exibe a sala de cinema onde seus corpos agora são imagens, ausentes e desterritorializadas. No cinema, a experiência se altera pela chegada das três atrizes, que corporificam as imagens descarnadas antes vivas somente na tela, operam uma reterritorialização e rompem o isolamento individual dos espectadores, instaurando um convívio que redimensiona a noção de coletividade pelas copresenças evidenciadas. As especificidades de cada arte são assim, primeiro, isoladas, de modo a que se percebam, e então retensionadas para forjar experimentos híbridos, liminares, irredutíveis à unidade. Entre os dois mosaicos desencontrados construídos pelas atrizes e diretora como peça e filme, a apreensão é fragmentada e descontínua, solicitando do espectador não só de Jatahy - uma operação de montagem constante.

\section{Referências Bibliográficas}

AUMONT, J. et al. A estética do filme. 3. ed. Campinas: Papirus, 2005. BOURRIAUD, N. Estética relacional. São Paulo: Martins Fontes, 2009. 
COMOLLI, J.-L. Ver e poder - a inocência perdida: cinema, televisão, ficção, documentário. Belo Horizonte: Editora UFMG, 2008.

CRARY, J. 24/7 Capitalismo tardio e os fins do sono. São Paulo: Cosac Naify, 2014.

DEBRAY, R. Vida e morte da imagem: uma história do olhar no Ocidente. Petrópolis: Vozes, 1993.

Filosofia del teatro I: convivio, experiencia, subjetividade. Buenos Aires: Atuel, 2007.

DESGRANGES, F. A inversão da olhadela: alterações no ato do espectador teatral. São Paulo: Hucitec, 2012.

DUBATTI, J. Convivio e tecnovivio: teatro entre infancia y babelismo, 2014. Disponível em: <http://www.dramateatro.com/index.php?option=com_content\&view=article\&id=38:jorgedubatti- 1 \&catid=13: monograficos-y-teoricos\&ltemid=579\&lan$\mathrm{g}=\mathrm{es}>$. Acesso em: 17 out. 2015.

FISCHER-LICHTE, E. Appearing as embodied mind - defining a week, a strong and a radical concept of presence. In: GIANNACHI, G.; KAYE, N.; SHANKS, M. (Orgs.). Archaeologies of presence: Art, performance and the persistence of being. Nova York: Routledge, 2012.

The transformative power of performance: a new aesthetics. Londres/ Nova York: Routledge, 2008.

Recebido em 24/10/2015

Aprovado em 26/10/2015

Publicado em 21/12/2015 